\title{
Nuclear localisation of NOVH protein: a potential role for NOV in the regulation of gene expression
}

\author{
B Perbal
}

\begin{abstract}
Aims-To identify the NOV protein detected by immunofluorescence in the nucleus of human cancer cell lines to establish whether targeting to the nucleus reflects dual paracrine and intracrine biological functions of NOV, as has been reported previously for several signalling peptides and proteins.

Methods-Nuclear and cytoplasmic fractions were prepared from 143 and HeLa cells in which nuclear NOV protein was detected. Western blotting analysis of NOV proteins in both types of fractions was performed using two NOV specific antibodies. Confocal microcoscopy was used to visualise the nuclear NOV protein in HeLa and 143 cells. A yeast two hybrid screening system was used to isolate cDNAs encoding proteins able to interact with the human NOV protein.
\end{abstract}

Results-A $31 / 32 \mathrm{kDa}$ doublet of NOV protein was identified in the nuclear fraction of 143 and HeLa cells. Because the antibodies were directed against the C-terminus of NOV, the $31 / 32 \mathrm{kDa}$ NOV isoform is probably truncated at the $\mathrm{N}$-terminus and might correspond to the secreted $32 \mathrm{kDa}$ NOV isoform detected in cell culture medium. Confocal microscopy indicated that in addition to the cytoplasmic NOV protein already identified, a nuclear NOV protein was present in both the nucleoplasm and nucleoli of Hela and 143 cells. Screening of cDNA libraries prepared from HeLa cells, Epstein-Barr virus transformed lymphocytes, and normal human brain showed that the NOV protein interacts with the $\mathbf{r p b} 7$ subunit of RNA polymerase in a yeast two hybrid system.

Conclusions-The NOV protein detected in the nucleus of 143 and HeLa cells is probably an N-terminus truncated isoform of the secreted $48 \mathrm{kDa} N O V$ protein. A growing body of evidence suggests that novH expression is closely associated with differentiation in normal human tissues and that the nov gene encodes a signalling protein that belongs to an emerging family of cell growth regulators. The nuclear localisation of a NOV isoform potentially provides an additional degree of signalling specificity. The interaction of the NOV protein and the $\mathbf{r p b} 7$ subunit of RNA polymerase II in the two hybrid system suggests that NOV might be involved in regulating gene expression at the transcriptional level. As has already been sug- gested for several other nuclearly located cytokines, the NOV protein does not contain a typical nuclear localisation signal. Therefore, it is possible that it combines with either a receptor or a chaperone during its translocation. Disruption of the balance between the secreted and nuclear NOV isoforms might affect the putative autocrine and paracrine functions of NOV and might be of considerable importance in the development of cancers in which the expression of novH has been shown to be impaired.

(F Clin Pathol: Mol Pathol 1999;52:84-91)

Keywords: nov gene; RNA polymerase II; cellular signals

The nov proto-oncogene (accession number X59284 ) was originally isolated as an integration site for the myeloblastosis associated virus type 1 (MAV-1 N) in avian nephroblastomas, ${ }^{1}$ which constitute a unique model of the human Wilms's tumour. ${ }^{2}{ }^{3}$ Expression of nov is increased in all chicken nephroblastomas ${ }^{3}$ and is also altered in all human Wilms's tumours. ${ }^{4}$

Recent results have established that novH expression is associated with differentiation during chondrogenesis (M Laurent et al, unpublished, 1999), muscular differentiation (Y Chérel et al, unpublished, 1999; C Martinerie et al, unpublished, 1999), and central nervous system development. ${ }^{5}$ Because nov expression is inhibitory to fibroblastic cell growth ${ }^{1}$ and is associated with cell quiescence, ${ }^{6}$ we have postulated that nov is involved in negative regulation of cell growth. ${ }^{3}$

The novH gene was reported previously to encode a secreted $48 \mathrm{kDa}$ protein, which is highly conserved throughout evolution. ${ }^{7-9} \mathrm{Se}-$ quence analysis of the NOV protein revealed that it shares extensive homology with two positive regulators of cell growth (CTGF/ FISP12 and CYR61/CEF10) reported to act cooperatively with growth factors. ${ }^{10-13} \mathrm{NOV}$ and these proteins were shown to contain 38 conserved cystein residues and four putative structural motifs, the biological function of which remains to be established.

The presence of an insulin-like growth factor (IGF) binding protein (IGFBP)-like motif at the C-terminus of $\mathrm{NOVH}$, and the extensive homology of NOV, CTGF, CYR61, and IGFBP3 at their 5 ' termini suggested that NOV might be acting in the IGF signalling pathway. In agreement with this hypothesis, it has been reported recently that CTGF binds IGF-I and IGF-II with low affinities. ${ }^{14}$ Although our preliminary results indicated that IGFs did not bind to recombinant NOV protein secreted by 
baculovirus infected SF9 cells, ${ }^{15}$ NOV and IGFBPs might share common signalling activities through IGF independent pathways, as reviewed recently for IGFBP3. ${ }^{16}{ }^{17}$

In the course of immunochemical studies aimed at establishing the location of the $\mathrm{NOVH}$ protein in normal and tumour tissues, we noticed a positive signal in the nucleus of various cell lines. This observation prompted us to determine whether, as already reported for several other signalling proteins, the NOVH protein is transported to the nuclear compartment and potentially participates more directly in the regulation of gene expression.

\section{Materials and methods}

CELLS

Human epitheloid carcinoma HeLa cells and human osteosarcoma $\mathrm{TK}^{-} 143$ cells were obtained from the American type culture collection (ATCC) and maintained in Dulbecco's Eagle's modified medium supplemented with $5 \%$ fetal calf serum.

CELL FRACTIONATION

HeLa and 143 cells grown to confluence in $150 \mathrm{~cm}^{2}$ culture flasks were rinsed twice with $100 \mathrm{ml}$ of cold phosphate buffered saline (PBS) and scraped in $50 \mathrm{ml}$ of cold PBS. All subsequent steps were performed at $4^{\circ} \mathrm{C}$. The cells were collected by centrifugation at $5000 \times g$ for five minutes and rinsed once with cold PBS. Each cell pellet was resuspended in $500 \mu \mathrm{l}$ of buffer A (10 mM Hepes (pH 7.4), $1.5 \mathrm{mM} \mathrm{MgCl}, 10 \mathrm{mM} \mathrm{NaCl}, 1 \mathrm{mM}$ phenylmethylsulphonyl fluoride (PMSF), $0.1 \mathrm{mM}$ $N$ - $\alpha$-p-tosyl-L-lysine chloromethyl ketone (TLCK), and $0.1 \mathrm{mM} \quad \mathrm{N}$-tosyl-Lphenylalanine chloromethyl ketone (TPCK)). The cells were lysed by the addition of Nonidet P-40 (Sigma, St Louis, Missouri, USA) to a final concentration of $0.1 \%$ and gentle mixing (five or six strokes with a P1000 pipette tip). The nuclei were pelleted at $4^{\circ} \mathrm{C}$ by a two minute centrifugation at $12000 \times g$ in an Ependorff microcentrifuge, and the cytoplasmic fraction (supernatant fluid) was carefully pipetted out and transferred to a new tube. The cytoplasmic fractions were centrifuged once more to eliminate remaining debris. The nuclear pellet was washed once with buffer A, collected by centrifugation, resuspended in $600 \mu \mathrm{l}$ of buffer C (10 mM Hepes (pH 7.4), $1.5 \mathrm{mM} \mathrm{MgCl}, 420 \mathrm{mM} \mathrm{NaCl}, 1 \mathrm{mM}$ PMSF, $0.1 \mathrm{mM}$ TLCK, and $0.1 \mathrm{mM}$ TPCK), and sonicated three times for 30 seconds at 20 kcycles/sec. The remaining debris was eliminated by centrifugation at $12000 \times g$ for two minutes and the nuclear fraction (supernatant) was collected.

\section{PRODUCTION AND PURIFICATION OF GST-CtNOV} PROTEIN

A glutathione $S$ transferase (GST)-CterNOV fusion protein (GST-CtNOV) was produced to generate another polyclonal antibody specific to the C-terminal end of the NOV protein. A 69 CtNOV double stranded oligonucleotide encoding the C-terminal end of the NOV pro- tein (KNNEAFLQELELKTTRGKM) was synthesised with an EcoRI and a Sal I site at the 5' and 3' end, respectively, to allow cloning in phase with GST in the Pharmacia pGEX-4T-2 vector (gift of Dr B He). Exponentially growing Escherichia coli BL21 cells (optical density of 0.6 at $600 \mathrm{~nm}$ in $2 \times$ YT medium) transformed with the GST-CterNOV plasmid were induced with $0.1 \mathrm{M}$ isopropyl- $\beta$-D-thiogalactopyranoside (IPTG) for 90 minutes at $37^{\circ} \mathrm{C}$. The harvested cells were lysed by sonication in PBS containing protease inhibitors $(0.3 \mathrm{mM}$ PMSF, $2 \mathrm{mM}$ benzamidine) and $0.1 \%$ 2-mercaptoethanol. After addition of Triton $\mathrm{X} 100$ to a final concentration of $1 \%$, the cell debris was clarified by centrifugation at 5800 $\times g$ in a SS34 Sorvall rotor for 20 minutes at $4^{\circ} \mathrm{C}$. The GST fusion protein contained in the supernatant was adsorbed to glutathioneagarose beads (Sigma) by mixing for one hour at $4^{\circ} \mathrm{C}$. It was then washed several times with PBS containing protease inhibitors, $0.5 \%$ nonfat milk, and $0.5 \mathrm{mM}$ ATP and was eluted with $10 \mathrm{mM}$ reduced glutathione (Sigma). The eluted protein was quantified with a Bio Rad protein assay kit (Bio Rad, Hercules, California, USA), bovine serum albumin (BSA) was used as a protein standard.

\section{ANTIBODIES}

The K19 polyclonal rabbit antibodies to the NOV C-terminus have been described previously. ${ }^{15}$ The biotinylated goat antirabbit antibodies were purchased from Sigma.

A total of $11 \mathrm{mg}$ of recombinant GSTCtNOV fusion protein was used for rabbit polyclonal antibody production according to standard protocols (Josman Laboratories, Napa, California, USA). The anti-GSTCtNOV antibodies recognise both the recombinant and native NOV protein as established by western blotting and competition assays (see results).

POLYACRYLAMIDE GEL ELECTROPHORESIS AND IMMUNOBLOTTING

Cytoplasmic and nuclear protein samples obtained from HeLa and 143 cells were separated by electrophoresis at $42 \mathrm{~mA}$ for three hours at room temperature in $12 \%$ polyacrylamide gels containing $0.1 \%$ sodium dodecyl sulphate (SDS) as described previously. ${ }^{18}$ The separation gel was prepared by mixing the following: $5.0 \mathrm{ml} 3.0 \mathrm{M}$ Tris $/ \mathrm{HCl} \quad(\mathrm{pH} 8.5)$, $16.9 \mathrm{ml}$ of a solution containing $280 \mathrm{~g} / \mathrm{l}$ acrylamide and $7.34 \mathrm{~g} / 1$ of bisacrylamide, $7.1 \mathrm{ml}$ distilled water, $10 \mathrm{ml} 0.14 \%$ ammonium persulphate, $0.4 \mathrm{ml} 10 \% \mathrm{SDS}$, and $12 \mu \mathrm{l}$ of $\quad \mathrm{N}, \mathrm{N}, \mathrm{N}^{\prime}, \mathrm{N}^{\prime}$-tetramethylethylenediamine (TEMED). The stacking gel was prepared by mixing the following: $3.0 \mathrm{ml} 0.8 \% \mathrm{SDS}$ in $1 \mathrm{M}$ Tris/ $\mathrm{HCl}$ ( $\mathrm{pH} 7.0), 3.5 \mathrm{ml}$ of a solution containing $280 \mathrm{~g} / 1$ acrylamide and $7.34 \mathrm{~g} / 1$ of bisacrylamide, $5.5 \mathrm{ml}$ distilled water, $12 \mathrm{ml}$ $0.14 \%$ ammonium persulphate, and $8 \mu \mathrm{l}$ TEMED. Gels were run for 150 minutes at 42 A (Power supply: E-C Apparatus Corporation Holbrook, New York, USA) in a buffer containing $3 \mathrm{~g} / 1$ Tris base, $14.4 \mathrm{~g} / 1$ glycine, and $4 \mathrm{~g} / 1 \mathrm{SDS}$. The proteins were transferred on to 

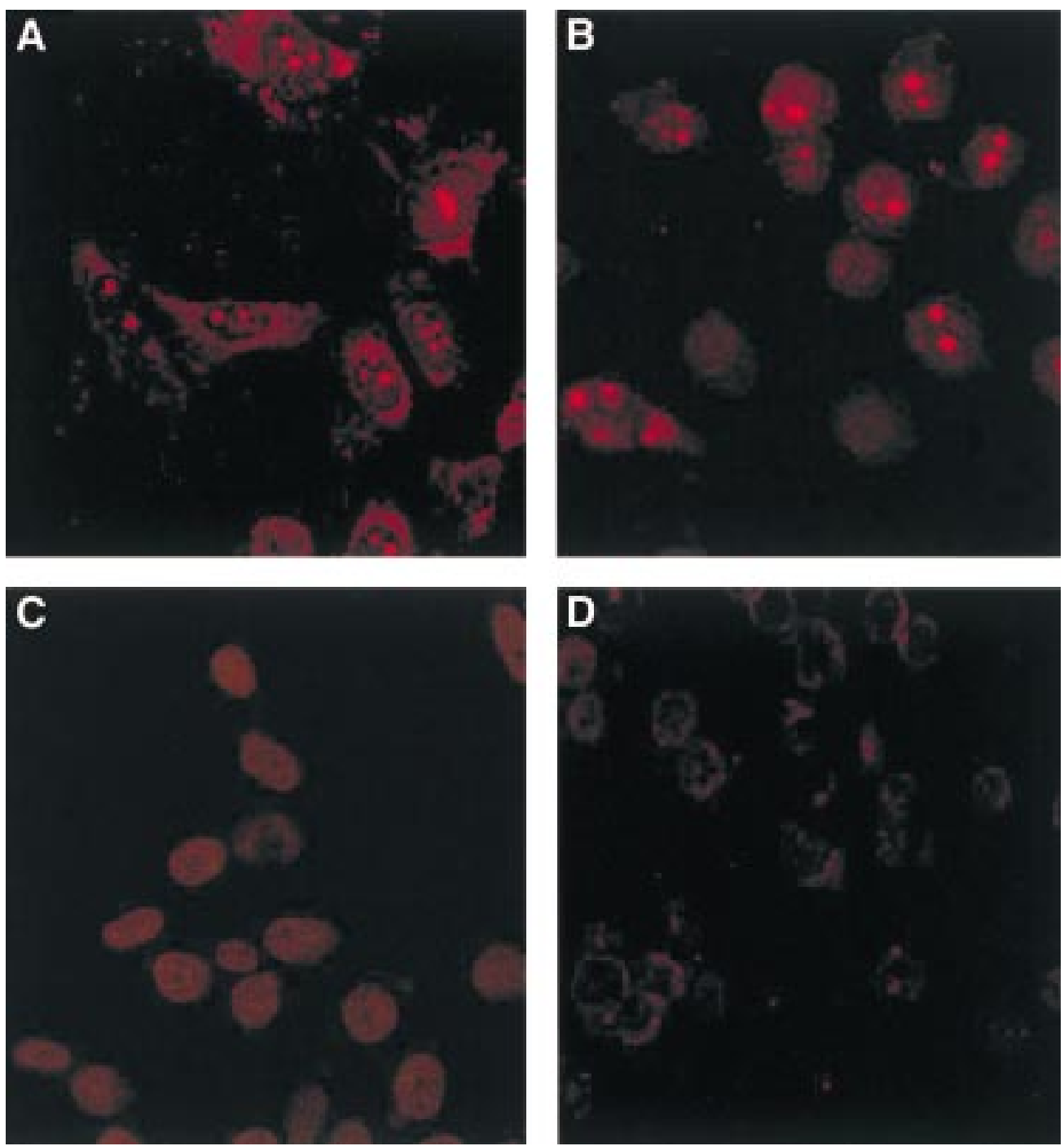

Figure 1 Detection of nuclear NOV proteins by indirect immunoflurescence. Confocal digital images of representative HeLa and 143 cells reacted with antibodies to the NOV protein. 143 cells (A), and HeLa cells (B) were reacted with anti-NOV antibody (K19), followed by biotinylated goat antirabbit antibodies and Texas red conjugated avidin. (C) 143 cells incubated with anti-NOV in the absence of secondary antibody and (D) HeLa cells reacted with anti-NOV antibody in the presence of competitor recombinant GST-CtNOV protein $(30 \mu \mathrm{g})$.

a nitrocellulose membrane overnight at $9 \mathrm{~V}$ $(50 \mathrm{~mA})$ in a Bio Rad transfer apparatus by immersing the plates in 41 transfer buffer containing $6.14 \mathrm{~g}$ Tris/ $\mathrm{HCl}, 7.4 \mathrm{~g}$ Tris base, $57.7 \mathrm{~g}$ glycine, $800 \mathrm{ml}$ methanol, and $3200 \mathrm{ml}$ distilled water. The position of the molecular weight markers on the membrane was visualised by staining in a $1 \%$ acetic acid solution containing $0.1 \%$ Ponceau red (Sigma) for five minutes. Non-specific binding was blocked by incubating the membrane for one hour in PBS containing 5\% (wt/vol) non-fat milk before a one hour incubation at room temperature in the presence of the K19 antibody (1/500 dilution). The blots were washed once in PBS containing 5\% non-fat milk for 15 minutes and four times for 10 minutes in PBS; they were then incubated for one hour at room temperature in a $1 / 3000$ dilution of goat antirabbit IgG-alkaline phosphatase conjugate (Bio Rad). The blots were washed as described above and developed according to the protocols supplied in the Bio Rad Laboratories kit.

\section{IMMUNOFLUORESCENCE}

Appproximately $5 \times 10^{4} \mathrm{HeLa}$ or 143 cells were seeded into wells on glass slides (Cell-line Inc, Newfield, New Jersey, USA) and incubated for 24 hours at $37^{\circ} \mathrm{C}$. The cells were then fixed in PBS containing 3.5\% paraformaldehyde, washed three times in TBS $(30 \mathrm{mM}$ Tris/ $\mathrm{HCl}(\mathrm{pH} 7.5), 150 \mathrm{mM} \mathrm{NaCl}$ ), and incubated in TBS containing $20 \%$ human serum and $1 \%$ BSA to avoid non-specific binding. The treated cells were then incubated in the presence of K19 antibody (diluted 1/250 in TBS containing $10 \%$ human serum) for two hours at room temperature and washed three times, with agitation, in TBS containing 10\% human serum. The slides were then reacted with the secondary antibodies for one hour at room temperature. For K19 detection, slides were incubated with a $1 / 200$ dilution of biotinylated goat antirabbit antibodies. Slides were then washed three times for five minutes each in PBS containing 10\% human serum and once in bicarbonate buffer $(20 \mathrm{mM}$ sodium 


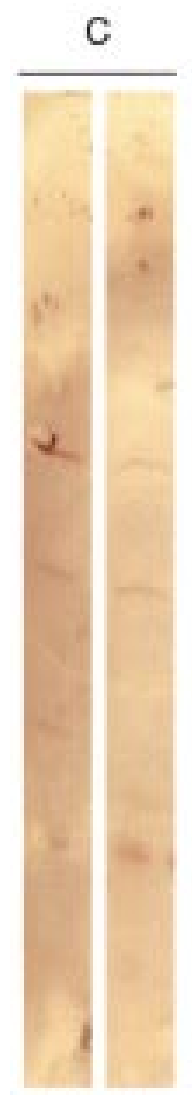

143 Hela

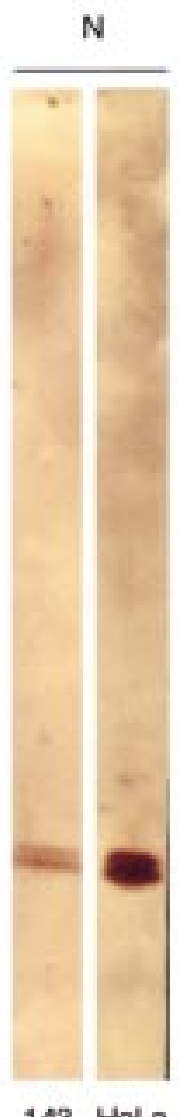

143 Hela

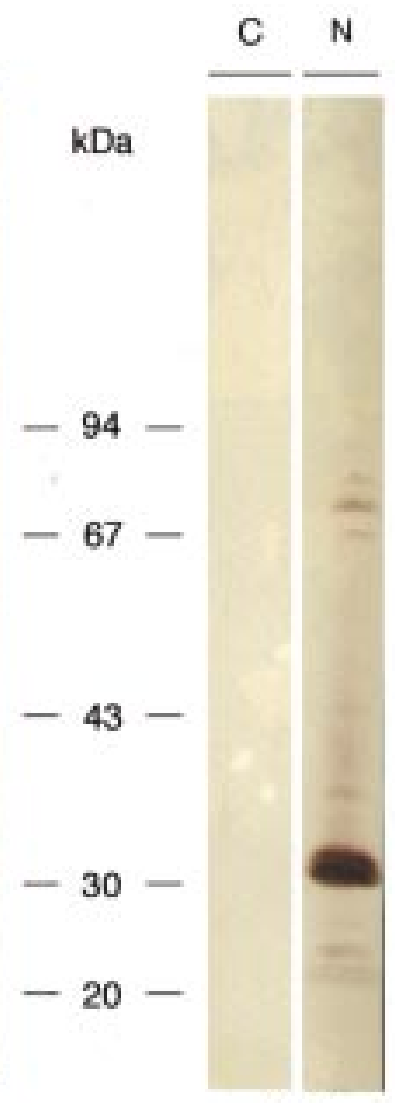

Hela

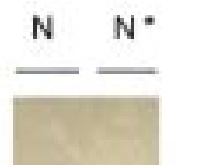

Palo Alto, California, USA) in frame with the DNA binding domain of Gal4. The resulting plasmid (pNOV) was used as a "bait" to screen three cDNA libraries (an Epstein-Barr virus (EBV) transformed human peripheral blood lymphocyte library (gift of Aviron Inc, Mountain View, California, USA), a HeLa cell library, and a normal human brain library from Clontech, all provided by Dr B Roizman), which were fused to the Gal 4 transcriptional activation domain in pGADGH. The pGBT9 bait and pGADGH plasmids were introduced sequentially into yeast strains HF7c or Y190 (provided by Dr B Roizman). Double transformants were selected on SD medium (Clontech) lacking tryptophan, leucine, and histidine, but containing $5 \mathrm{mM}$ (for HF7c strain) or $25 \mathrm{mM}$ (for Y190 strain) 3-amino-1,2,4triazole (3AT). After incubation at $30^{\circ} \mathrm{C}$, positive colonies were restreaked on the same media and then tested for $\beta$-galactosidase activity by filter assay (under conditions recommended by Clontech). Blue colonies were grown in SD medium (Clontech) lacking leucine. Library plasmids were isolated and electroporated into $E$ coli $\mathrm{HB} 101$ using a Bio Rad Gene Pulser II, (capacitance 25, $1.80 \mathrm{kV}$, $200 \Omega$, with a constant time in the range of 3.0-3.2). Bacterial transformants were selected on M9 minimal medium containing $50 \mu \mathrm{g} / \mathrm{ml}$ ampicillin, $40 \mu \mathrm{g} / \mathrm{ml}$ proline, $1 \mathrm{mM}$ thiamine, $0.4 \%$ glucose, and a mixture of amino acids lacking leucine. The purified plasmids were co-transformed with pGBT9 or pLAM5' encoding a human lamin (Clontech) into HF7c cells as controls to eliminate false positives. The pNOV bait plasmid co-transfected with the pGADGH plasmid alone was also negative for $\beta$-galactosidase activity.

The nucleotide sequences of the cDNAs encoding proteins able to interact with the NOV protein in the two hybrid system were established with the T7 sequenase v2.0 kit from Amersham Life Sciences (Cleveland, Ohio, USA). Sequence homologies were searched with BLAST (National Center for Biotechnology Information).

\section{Results}

A NUCLEAR NOV PROTEIN IS DETECTED IN THE NUCLEUS OF HeLa AND 143 CELLS

To determine whether the NOV protein could be detected in the nucleus of subconfluent cells, fixed 143 and HeLa cells were exposed to the anti-NOV K19 rabbit antibody and then to biotinylated goat antirabbit immunoglobulin, followed by avidin bound to Texas red. In parallel experiments, cells treated with the antiNOV K19 antibody were incubated directly with goat antirabbit Texas red conjugated antibodies.

The rationale for choosing HeLa and 143 cell lines was that: (1) the human novH gene was originally cloned from a HeLa cDNA library, ${ }^{4}$ and (2) we have obtained evidence suggesting that NOV is involved in bone formation (M Laurent et al, unpublished, 1999).

Nuclei from both 143 (fig 1A) and HeLa (fig 1B) cells showed a strong positive response to amplified by the polymerase chain reaction (PCR) and inserted into pGBT9 (Clontech,

YEAST TWO HYBRID SYSTEM

A yeast two hybrid screening system was used to isolate cDNAs encoding proteins able to interact with the human NOV protein. A DNA fragment encoding nov codons 29 to 357 was 
Clone I2

GCNCGAGTGG ATTCCCNGGG ACTGNCGGAN GTGTGGACTC TGGCTGNCTA CCTGGTCTGG GAAGATGTTC TACCATATNT CCCTAGAGCA CGAAATCCTG CTGCACCCGC GCTACTTCGG CCCCAACTTG CTCAACACGG TGAAGCAGAA

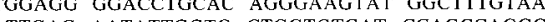
TTGCTGTCAC CACCATTGAC AATAT GGT CTOGTGTOAT CCAGCCAGGC CGAGGCTTTO TCCTTTATCC AGTTAAGTAC AAGGCCATHG TTTCCGGCC ATTTAAAOGG GAGGTCGTGG ATGCTOTTOT CACTCAOGTC AACAAGGTTO GACTCTTCAC AGAAATTGTO COCATGTCTT GCTTCATCTC TCOACATTCC ATCCCTTCAG AATGGAGTTT GATCCTAACT CAACCACCAT GTTACAAGAC AATGGATGAG GATATTGTGA TANCAGACNA TGAGATCGC

Clone 30

GCACGAGCTC TGCCTGCCTA CCTGGTCTGG GAAGATGTTC TACCATATCT CCCTAGAGCA CGAAATCCTG CTGCACCCGC GCTACTTCGG CCCCAACTTG CTCAACACGG TGAAGCAGAA GCTCTTCACC GAGGTGGAGG GGACCTGCAC AGGGAAGTAT GGCTTTGTAA TTGCTGTCAC CACCATTGAC AATATTGGTG CTGGTGTGAT CCAGCCAGGC CGAGGCTTTG TCCTTTATCC AGTTAAGTAC AAGGCCATTG TTTTCCGGCC ATTTAAAGGG GAGGTCGTGG ATGCTGTTGT CACTCAGGTC AACAAGGTTG GACTCTTCAC AGAAATTGGG CCCATGTCTT CACTCAOOTC AACAAGOTO OACRCTCAC AGAAATGG CCCATGTCT GCTTCATCTT CGACATTCCA TCCCTTAGAN TGGGAGTTTG MTCCTAACTC CACCCCCATG TTACAAGAAA TGGATNAGA

\section{Clone 34}

AACCTGGATC CTGCCGGGNC NGCACTCCCA CTTNCCAGGC ACCCTGGANC CTGCCACTAC TGGAGAGGTC TCCAAATGAC ATCCCAAGGA CCTACCTCTG TCCTCTGTGA GCACAAACAG AGATGCAGGG TGCCTAGGGC TCAGAGGACC AGACGGGGGC AGGACCCAGC CTGCCTAGTT CCCTGTCGTT TGTTCCCTTG CTGTGGCCAT TGCTGCCATC TCCTGNNCAT TGAAATTCCG GCCATTTAAA GGGGAGGTCG TGGATGCTGT TGTCACTCAG GTCAACAAGG TTGGACTCTT CACAGAAATT GGGCCCATGT CTTGCTTCAT CTCTCGACAT TCCATCCCTT CAGAGATGGa GTTTGATCTA ACTCAACACC ATGTTACAAG ACAATGGATG ANGATATTGN GATCAGCAGG ACGATGAGAT CCGTTAANGA TTGTGGGNCC

Figure 3 Nucleotide sequence of the cDNA clones encoding rpb7 related proteins interacting with NOV in the two hybrid system. The nucleotide sequence is indicated from 5' to 3'. Use of the BLAST program established that these sequences match completely the published sequence of the rpb7 subunit of human RNA polymerase II. The GGGAGGG motif has been highlighted in the different sequences to allow a rapid comparison of the clones.

K19 anti-NOV antibody. In these cells, the nuclear NOV protein appeared to be localised to the nucleolus and nucleoplasmic discrete dense bodies, and the staining pattern was reminiscent of that seen for several transcriptional transactivators and splicing factors. Weak staining was also seen at the periphery of the nucleus and in the cytoplasm of these cells.

A $31 / 32 \mathrm{kDa}$ NUCLEAR ISOFORM OF NOV IS DETECTED BY WESTERN BLOTTING IN THE NUCLEAR FRACTION OF HeLa AND 143 CELLS Because nov mRNA expression was shown to be stimulated upon growth arrest, ${ }^{6}$ both HeLa and 143 cells were grown until they had reached confluence. They were then collected and nuclear and cytoplasmic fractions were prepared. Protein samples $(250 \mu \mathrm{g}$ each of nuclear and cytoplasmic proteins) were separated by three hour electrophoresis at $62 \mathrm{~mA}$ $(160 \mathrm{~V})$ in $12 \%$ polyacrylamide gels. To perform western blot analysis, the separated proteins were electrically transferred on to nitrocellulose ( $50 \mathrm{~mA}$ ( $9 \mathrm{~V}$ ) for 9.5 hours), and the resulting blot was treated for $\mathrm{NOV}$ immunodetection with affinity purified K19 antibody and anti-GST-CtNOV antibody.

A $31 / 32 \mathrm{kDa}$ NOV related polypeptide doublet gave rise to a strong positive signal in both 143 and HeLa nuclear extracts when both the K19 (fig 2A) and anti-GST-Ct NOV were used (fig 2B). This band was totally absent when the samples were preincubated with recombinant GST-CtNOV protein, as a result of competition (fig 2C). A NOV protein of a similar size has also been detected: (1) in total cell extracts of different origins, (2) in conditioned culture medium from normal and tumour cells, and (3) a $25 \mathrm{kDa}$ NOV protein has been found in the culture medium of SF9 cells infected with a nov expressing recombinant baculovirus (our unpublished results, 1998)..$^{15}$ The presence of two potential sites of $N$-glycosylation at positions 97 (NQTG) and 280 (NCTS) in the NOV protein was previously proposed to account for the detection of a $43 / 46 \mathrm{kDa}$ NOV doublet in Madin Darby canine kidney transfected cells. ${ }^{15}$ The detection of a $31 / 32 \mathrm{kDa}$ doublet in the nuclear fractions suggests that the C-terminal fragment of NOV might be glycosylated in these cells.

Based on the fact that the nov recombinant baculovirus expresses a full length nov mRNA and on the lack of evidence for novH alternative splicing, the $31 / 32 \mathrm{kDa}$ protein is likely to originate from post-translational processing of the $46 / 48 \mathrm{kDa}$ NOV protein. Because the full length NOV protein is secreted, ${ }^{15}$ nuclear localisation of the $31 /$ $32 \mathrm{kDa}$ protein might require the $48 \mathrm{kDa}$ isoform to be processed outside of the cell or at the cell membrane.

THE NOV PROTEIN INTERACTS WITH THE rpb7 SUBUNIT OF RNA POLYMERASE IN A YEAST TWO HYBRID SYSTEM

When the two hybrid system described above was first used to screen a normal human brain cDNA library and an EBV transformed human peripheral blood lymphocyte cDNA library with Y 190 yeast cells, 91 and 58 histine positive colonies were obtained, respectively. Among 
them, seven clones from the lymphocyte library and one clone from the brain library that expressed high levels of $\beta$-galactosidase activity were used for $E$ coli transformation and sequencing. The third screening was performed with a HeLa cell library and both the HF7c and Y190 yeast strains. A total of 220 (H1-H220) and 105 (Y1-Y105) histidine positive colonies were picked from Y190 and HF7c transformations, respectively. Among these, 75 and 37 colonies that were highly positive for $\beta$-galactosidase activity were selected for $E$ coli transformation and sequencing.

The sequence of the 3' end of the inserts (at the 5' boundary of the Gal4 DNA domain fusion) was established for several clones (B Perbal et al, unpublished, 1998). We found that the nucleotide sequence of clone 12 isolated from the lymphocyte library and the nucleotide sequences of clones $\mathrm{H} 30, \mathrm{H} 34, \mathrm{H} 35$, and $\mathrm{Y} 1$ obtained from the HeLa library (fig 3 ) matched completely the published sequence of the human RNA polymerase II subunit (rpb7). Clones 12, H30, H34, H35, and Y1 were 100\% identical to the $\mathrm{rpb} 7$ sequence over 450,415 , 206,336 , and 618 nucleotides, respectively. It has been established previously that the $\mathrm{rpb} 7$ subunit alone did not give rise to false positives under the conditions used ( $M$ Werner, personal comunication, 1998).

Because these results have been obtained in three independent screenings, they strongly suggest the interesting possibility that a nuclear form of the NOV protein might interact with RNA polymerase II in higher eukaryotic cells and that the $31 / 32 \mathrm{kDa}$ nuclear form of the NOV protein might be responsible for this interaction.

\section{Discussion}

There is a growing body of evidence suggesting that under normal conditions, the NOV protein is involved in the differentiation of several cell types, namely: (1) in the human kidney, the NOV protein is increasingly detected in tubules as they differentiate and is found to accumulate in podocytes during glomerular differentiation ${ }^{15} ;(2)$ nov expression itself has been shown to be closely associated with chicken chondrocyte differentiation, both ex vivo and in vivo ( $M$ Laurent et al, unpublished, 1998); (3) during human central nervous system development, the expression of novH increases with terminal differentiation of somatomotor neurons. ${ }^{5}$

Based on structural considerations, we and others have hypothesised that the biological role of NOV and related proteins (CTGF and CYR61) results from their secretion and ability to interact with either IGF, nuclear matrix components, or growth factor receptors. The detection of NOV isoforms in the nucleus of HeLa and 143 human cells opens interesting prospects as to the role of NOV in the regulation of differentiation.

Nuclear localisation of growth factors and peptide hormones once thought to act only outside of cells has been reported in an increasing number of cases over the past two decades, ${ }^{19}$ suggesting that these factors may act through direct interactions in the nuclei of target cells in addition to their participation in conventional signal transduction pathways. Among these, fibroblast growth factors (FGFs), IGF-I and IGFBP3 are of particular interest with respect to NOV.

Depending on cell type and context, FGFs were shown to stimulate either proliferation, differentiation, cell motility, or cell survival via their interactions with a series of high affinity cell surface receptors triggering signal transduction cascades leading to the regulation of gene expression in target cells. Apart from this paracrine effect, FGFs have been thought to act via intracrine effects after translocation to the cell nucleus. ${ }^{20}{ }^{21}$ For FGF3, it has recently been proposed that import into the nucleus versus the endoplasmic reticulum may depend upon the site of initiation of translation, and the presence of a bipartite nuclear signal and two C-proximal motifs implicated in cellular targeting. ${ }^{20}$ Although the NOV protein does not contain a conventional nuclear localisation signal, its nucleolar detection is reminiscent of a situation reported previously for FGF3. Sequence analysis (M Laurent and R Sainson, personal communication, 1998) revealed that NOV contains a basic KKGKKCLRTKKS motif, which might correspond to the FGF C-terminal motif 4, likely to play a crucial role in nuclear localisation.

Insulin binds to cell surface tyrosine kinase receptors to induce signal transduction. Recent experiments have established that although insulin does not contain a nuclear localisation signal, it can also be found in the cytoplasm and nucleus of cells, ${ }^{19}$ and have also suggested that this hormone peptide might be internalised via invaginations of the plasma membrane known as caveolae. Immunogold detection of NOV in cytoplasmic vesicles of as yet unkown origin (our unpublished observations, 1998) would be in agreement with NOV being internalised via a similar mechanism. Along this line, it will be interesting to establish whether nuclear translocation of the $\mathrm{N}$-truncated NOV isoform requires interaction with a nuclear localisation signal containing or nuclear localisation signal deprived receptor or chaperone.

IGFBP3, which contains a putative nuclear localisation signal, is also internalised and accumulates in the endosomal compartment in resting cells, whereas it is targeted to the nuclear compartment when cells proliferate. ${ }^{19}$ This suggests that nuclear localisation of such signalling proteins might be dependent upon the differentiation state of the target cells. Because IGFBPs and NOV share several structural traits, including a putative IGF binding signal and a striking conservation of cysteins at their $\mathrm{N}$-terminus, we proposed that they might also act along the same biological regulatory pathway(s). ${ }^{3}$ However, their functions in the nuclear compartment are likely to be very different because a full length IGFBP3 protein $^{22}$ and a truncated NOV protein are translocated to the nucleus. Because the nuclear $31 / 32 \mathrm{kDa}$ NOV protein was detected with the $\mathrm{C}$-terminus specific $\mathrm{K} 19$ antibody, it is 
probably an $\mathrm{N}$-truncated isoform. Because the antibodies used cannot detect the $\mathrm{N}$-proximal portion of $\mathrm{NOVH}$, it will be interesting to establish whether the $15 \mathrm{kDa}$ part of $\mathrm{NOVH}$ which is highly similar to the N-terminus of IGFBP 3 is also present in the nucleus.

It is also of interest that IGFBP5 shows nuclear localisation ${ }^{23}$ : the extracellular binding protein is taken up and translocated to the nucleus, probably through a common receptor with IGFBP3.

Nuclear localisation of most secretory regulatory proteins appears to require prior externalisation. A truncated NOV related protein with a $31 / 32 \mathrm{kDa}$ apparent molecular weight was also detected in conditioned medium of various cell lines. A $25 \mathrm{kDa}$ NOVH protein is also present in culture medium from baculovirus infected cells. This suggests that proteolytic cleavage of NOV occurring at about 135 residues from the $\mathrm{N}$-terminus is responsible for generating this shorter NOV protein. Proteolytic cleavage has also been shown to occur in IGFBP3 and to give rise to an N-truncated protein. ${ }^{24}$ It would be interesting to determine whether proteolytic cleavage of NOV is involved in or required for nuclear localisation of a truncated isoform. The observation that accumulation of the $31 / 32 \mathrm{kDa}$ isoform does not occur when secretion of the $48 \mathrm{kDa} N O V$ is impaired (our unpublished observations, 1998) would favour such a possibility.

It is likely that a $32 \mathrm{kDa}$ truncated NOV protein was expressed in one MAV induced nephroblastoma. Molecular cloning of the corresponding cDNA in recombinant retroviral vectors enabled us to establish that the $\mathrm{N}$-truncated NOV protein was oncogenic, whereas the presence of full length NOV correlated with cell growth arrest. ${ }^{1}$ Because expression of the nov gene is correlated strongly with the control of cell differentiation, overproduction of a truncated NOV might increase the amount of nuclear NOV and result in cell growth deregulation.

Although the biological importance of NOV nuclear targeting remains unclear, we would expect that the $31 / 32 \mathrm{kDa} N O V$ isoform interferes directly or indirectly with gene expression during normal development. Our finding that NOV probably interacts with the rpb7 subunit of RNA polymerase II in a yeast two hybrid system would be in agreement with the hypothesis put forward previously regarding the possible role of nuclearised hormones and growth factors in the regulation of transcription, translational control, and mRNA transport. ${ }^{19}$ Experiments currently in progress should establish whether an N-truncated NOV protein interacts with $\mathrm{rpb} 7$ in the nucleus of higher eukaryotic cells and whether this interaction results in modulation of RNA polymerase II transcriptional activity.

Because the amount of nuclear NOV protein was found to vary greatly (from nil to high concentrations) among various cell lines (our unpublished observations and PN Schofield, personal communication, 1998), the nuclear localisation of NOV might be related to proliferative status and stage of the cell cycle.
Because NOV is a member of an emerging family of cell growth regulators, including CTGF and CYR61, it could be assumed that nuclear isoforms of these proteins might also be targeted to the nucleus and play a dual paracrine and intracrine biological role.

Most of the experiments reported in this manuscript have been carried out in the Kovler Viral Oncology Laboratory of the University of Chicago and funded by a grant to the University of Chicago from the National Cancer Institute (CA71933) of the United States Public Health Services. I am indebted to Professor B Roizman for his constant support and for providing the opportunity for me to perform this work during two short term tays in his laboratory. Part of the sequencing was performed in stays in his laboratory. Part of the sequencing was performed in the Laboratoire d'Oncologie Virale et Moleculaire and in the Service de Biochimie et de Genetique Moleculaire (CEA Saclay). This project was also funded by grants from Ligue Nationale Contre le Cancer (Comité National, Comité du Cher et Comite de l'Indre), and Association pour la Recherche sur le Cancer (ARC). Thanks to Dr A Sentenac and M Werner for roviding sequencing facilities, $P$ Ward for advice and help with confocal microscopy, Dr B He for help and stimulating discussions, V Galvan for invaluable help with western blotting, and Dr C Martinerie and R Sainson for their participation in sequencing. I am grateful to $S$ Gabaron for grammar corrections.

1 Joliot V, Martinerie C, Dambrine G, et al. Proviral rearrangements and overexpression of a new cellular gene (nov) in myeloblastosis-associated virus type 1 -induced nephroblastomas. Mol Cell Biol 1992;12:10-21.

2 Perbal B. Pathogenic potential of myeloblastosis associated viruses. Infectious Agents and Disease 1995;4:212-27.

3 Perbal B. Contribution of MAV-1-induced nephroblastoma to the study of genes involved in human Wilms's tumor development. Crit Rev Oncog 1995;5:589-613.

4 Martinerie C, Huff V, Joubert I, et al. Structural analysis of the human nov proto-oncogene and expression in Wilms tumor. Oncogene 1994;9:2729-32.

5 Su B-Y, Cai W-Q, Zhang C-G, et al. A developmental study of novH gene expression in human central nervous system. of novH gene expression in human

6 Scholz G, Martinerie C, Perbal B, et al. Transcriptional down regulation of the nov proto-oncogene in fibroblasts transformed by p60v-src. Mol Cell Biol 1996;16:481-6.

7 Snaith M, Natarajan D, Taylor L, et al. Genomic structure and chromosomal mapping of the mouse nov gene. Genomics 1996;38:425-8.

8 Martinerie C, Viegas-Pequignot E, Guenard I, et al. Physical mapping of human loci homologous to the chicken nov proto-oncogene. Oncogene 1992;7:2529-34.

9 Ying Z, King ML. Isolation and characterization of xnov, a Xenopus laevis ortholog of the chicken nov gene. Gene 1996;171:243-8.

10 Ryseck RP, Macdonald-Bravo H, Mattei MG, et al. Structure, mapping, and expression of fisp-12, a growth factor-inducible gene encoding a secreted cysteine-rich protein. Cell Growth Differ 1991;2:225-33.

11 O’Brien TP, Yang GP, Sanders L, et al. Expression of cyr61, growth factor-inducible immediate-early gene. Mol Cell Biol 1990;10:3569-77.

12 Simmons DL, Levy DB, Yannoni Y, et al. Identification of a phorbol ester-repressible v-src-inducible gene. Proc Natl Acad Sci USA 1989;86:1178-82.

13 Martinerie C, Viegas-Pequignot E, Van-Cong $\mathrm{N}$, et al. Chromosomal mapping and expression of the human CYR61 gene in tumor cells from the nervous system. Mol Pathol 1997;50:310-17.

$14 \mathrm{Kim}$ HS, Nagalla SR, Oh Y, et al. Identification of a family of low-affinity insulin-like growth factor binding proteins IGFBPs): characterization of connective tissue growth factor as a member of the IGFBP superfamily. Proc Natl Acad Sci USA 1997;94:12981-6.

15 Chevalier G, Yeger H, Martinerie C, et al. novH: differential expression in developing kidney and a marker of heterotypic differentiation in Wilms's tumor. Am $f$ Pathol typic differentiation

16 Lalou C, Lasserre C, Binoux M. A proteolytic fragment of insulin-like growth factor (IGF) binding protein 3 that fails to bind IGFs inhibits the mitogenic effects of IGF-I and insulin. Endocrinology 1996;137:3206-12.

17 Oh Y, YamanakaY, Kim H-S, et al. IGF-independent actions of IGFBPs. In: Takano K, Hizuka N, Takahashi S-I, eds. Molecular mechanisms to regulate the activities of insulin-like growth factors. Amsterdam: Elsevier, 1998:125-33.

8 Perbal B. A practical guide to molecular cloning. New York: Wiley and Sons, 1988

19 Henderson JE. At the cutting edge. Nuclear targeting of secretory proteins. Mol Cell Endocrinol 1997;129:1-5.

20 Antoine M, Reimers K, Dickson C, et al. Fibroblast growth factor 3, a protein with dual subcellular localization, is targeted to the nucleus and nucleolus by the concerted action of two nuclear localization signals and a nucleolar retention signal. F Biol Chem 1997:272:29475-81.

$21 \mathrm{Li} \mathrm{W}$, Fawcet J, Widmer HR, et al. Nuclear transport of insulin-like growth factor-I and insulin-like growth factor 
binding protein-3 in opossum kidney cells. Endocrinology 1997; 138:1763-6.

22 Jaques G, Noll K, Wegman B, et al. Nuclear localization of insulin-like growth factor binding protein 3 in a lung cancer cell line. Endocrinology 1997;138:1767-7

23 Schedlich LJ, Young TF, Firth SM, et al. Insulin-like growth factor binding protein (IGFBP-3 and IGFBP-5) share a common nuclear transport pathway in T47D human breast carcinoma cells. F Biol Chem 1998;273:18347-52.

24 Lalou C, Sawamura B, Segovia B, et al. Proteolytic fragments of insulin-like growth factor binding protein-3: $\mathrm{N}$-terminal sequences and relationships between structure and biological activity. C R Acad Sci III 1997;320: 621-8.

\section{Fournal of Clinical Pathology - http://www.molpath.com}

Visitors to the world wide web can now access the fournal of Clinical Pathology either through the BMJ Publishing Group's home page (http://www.bmjpg.com) or directly by using its individual URL (http://www.molpath.com). There they will find the following:

- Current contents list for the journal

- Contents lists of previous issues

- Members of the editorial board

- Information for subscribers

- Instructions for authors

- Details of reprint services.

A hotlink gives access to:

- BMJ Publishing Group home page

- British Medical Association web site

- Online books catalogue

- BMJ Publishing Group books.

The web site is at a preliminary stage and there are plans to develop it into a more sophisticated site. Suggestions from visitors about features they would like to see are welcomed. They can be left via the opening page of the BMJ Publishing Group site or, alternatively, via the journal page, through "about this site". 